\title{
Learning Collectives With/In Sites of Practice: Beyond Training and Professional Development
}

\author{
Kathleen Kummen and B. Denise Hodgins
}

\begin{abstract}
Kathleen Kummen is both an instructor in the School of Education and Childhood Studies and chair of the Centre for Inquiry and Innovation in Childhood Studies at Capilano University on the unceded territorial lands of the Squamish and Tsleil-Waututh First Nations. She has worked in the early years field for over 25 years holding a variety of positions, including early childhood educator, child life therapist, and child care licencing officer. Kathleen's work draws on the reconceptualist movement in early childhood education, postfoundational theory in early childhood, and exploring theory and practice in the education of preservice educators. Email:kkummen@capilanou.ca
\end{abstract}

B. Denise Hodgins is the pedagogical consultant for the Ontario Centre of Excellence for Early Years and Child Care, a co-director in the BC Early Childhood Pedagogy Network, and the pedagogist and lead researcher at University of Victoria Child Care Services on the unceded territorial lands of the Lkwungen-speaking peoples. Her research interests include gender and care as materialdiscursive phenomena and the implications that common worlds research and pedagogy hold for early childhood.

Email: denise.hodgins@uwo.ca

This article describes an initiative that extended the Investigating Quality (IQ) Project's model of pedagogical development to a partnership between local ECE programs and their ongoing professional learning and an ECE training institution and its preparation of student educators. We begin with an overview of the project and pedagogical development model, describing how it conceptualizes and promotes professional learning as coconstructed in socio-material-historical-cultural-political contexts. We follow this with an analysis of the model's three key conditions: inquirybased learning, making learning visible, and pedagogical facilitation support. We conclude with considerations for what this model of pedagogical development might mean for the ECE profession.

Key words: early childhood education; professional development; early childhood teacher education; pedagogical practices; collective learning
This article shares the practice conditions and experiences of educators and student educators in a collaborative initiative that extended a professional development project in British Columbia called the Investigating Quality (IQ) Project, which began in 2005. In one of the IQ Project's sites, formal involvement in the project grew to include a partnership between an early childhood education (ECE) program and their educators' ongoing professional learning and an ECE training institution and its preparation of student educators. As the IQ Project's coordinator/evaluator (Denise) and the university ECE program's coordinator (Kathleen), we share the IQ Project's model of pedagogical development-and the specificities of the collaborative initiative that emerged within the project-as an example of professional learning that is embedded in local contexts and works to challenge bounded, linear hierarchies (i.e., of the ECE student, educator entering practice, and experienced educator).

Drawing on a report published by Eurofound, Michel Vandenbroeck and colleagues Peeters, Urban, and Lazzari (2016) list four factors for successful continuous professional development:

- a coherent pedagogical framework or learning curriculum that builds on research and addresses local needs

- the active involvement of practitioners in the process of importing education practice enacted within their settings 
- a focus on the practice-based learning taking place in constant dialogue with colleagues, parents, and local communities

- the provision of enabling working conditions, such as the availability of paid hours for non-contact time (e.g., for professional development) and the presence of a mentor or coach who facilitates practitioners' reflection in reference groups.

In this article we present the IQ Project's model as an example of an initiative that has aimed to facilitate these four factors in local communities of practices. Second, we examine the collaborative initiative that developed within the larger IQ Project as a possible pathway for moving beyond training and professional development as isolated, single events completed over a set, singular period of time. This collaboration highlights how bringing ECE training programs and ongoing professional development together within a situated collective of learning enhances the professional learning of students and educators at diverse places in their practice, which consequently contributes to children's lives and futures.

We begin with an overview of the IQ Project to provide a detailed description of how professional learning is conceptualized, promoted, and facilitated through the project. This is followed by an analysis of the collaboration between the ECE program and the ECE training institutions to demonstrate the IQ Project's model for promoting and implementing pedagogical development as coconstructed becomings situated in socio-material-historicalcultural-political contexts. In this analysis we look at three key conditions for living such a practice: inquiry-based learning, making learning visible, and pedagogical facilitation support. We conclude with some considerations of what this model of pedagogical development might produce when we move beyond the training and professional development of early childhood educators as a defined, finite period of time or a single, isolated event.

\section{Overview of the Investigating Quality Project}

The Investigating Quality (IQ) Project in British Columbia began in 2005 in an effort to broaden and deepen discussions about quality in early learning and care (Pacini-Ketchabaw \& Pence, 2005, 2011; Pence \& PaciniKetchabaw, 2006). The project has grown a model of pedagogical development based on international theories and research that promotes the active engagement of early childhood educators in critical reflection and actions as integral to the formation of sustainable and innovative ECE environments (Dahlberg, Moss, \& Pence, 2013; Rinaldi, 2006). This model utilizes monthly learning circles (LCs) in each site for groups of educators in the community to come together to critically reflect on their established and emerging practice through pedagogical narrations (Government of British Columbia, 2008b; Pacini-Ketchabaw, Nxumalo, Kocher, Elliott, \& Sanchez, 2015). Pedagogical facilitators lead LC discussions about contemporary theoretical perspectives related to the field and various approaches to curriculum and pedagogy (e.g., experimental, situated, innovative, responsive). Pedagogical facilitators connect and share resources with the participating educators in regular centre visits and through online spaces to support the educators' process of enacting their ongoing critical reflections and the LC discussions in practice. This model has been shaped by 12 years of IQ Project practice and research (PaciniKetchabaw \& Hodgins, 2017; for evaluation reports see http://www.veronicapaciniketchabaw.com/reports/).

During the 2016-2017 academic year, the IQ Project took place at sites in three locations in BC, with a pedagogical facilitator supporting a cluster of ECE programs in each site. One of these sites is made up of a cluster of programs within a large nonprofit child care society. At the time of writing, three of the society's 3-to 5-year-old classrooms had participated in the IQ Project for six years, and a fourth classroom (a toddler program) had participated for the last three years. This society also supports student educators through practicum placements for a local university's ECE program, and in 2016 an opportunity arose to bring these two pedagogical development pathways 
together in a more concerted way.

The pedagogical facilitator who works in this site is also teaching faculty within the university's ECE program, and for the 2016-2017 academic year the university contributed to the IQ Project by financially supporting the pedagogical facilitator role as a teaching section over two terms. With the support of the university, the ECE program was motivated to participate because the project's practices are consistent with the department's belief that student educators should be learning with/in, not learning about, pedagogies (Kummen, 2014; Lenz Taguchi, 2010). To move toward this goal, the department piloted having a consistent faculty member in the role of pedagogical facilitator who works with educators in the field and student educators over the course of an academic year. The society contributed to this new relationship by taking two of the university's practicum students in each of the project's participating four centres, and by creating space for 10 students to be in the centre one morning a week as a part of an observing and recording course and 26 students to be in one of the centres once a week for five weeks to participate in a short-term project as part of a curriculum course. For consistency, these courses were also part of the pedagogical facilitator's teaching load. The analysis that we share focuses on this IQ Project site with the university-community partnership. The qualitative data we draw on in this article is from the project's end-of-year evaluation surveys and focus group discussions with participating educators for this site, as well as the university's student feedback as part of their completed course assignments and unsolicited emails to the ECE program coordinator and the faculty dean.

\section{(Re)conceptualizing professional learning}

As noted, the IQ Project developed as an initiative to broaden and deepen discussions about quality in ECE, which included the promotion and active engagement of educators in critical reflection and situated (localized) pedagogical actions. The project leans on the reconceptualizing early childhood movement, which brought postfoundational theories to ECE that challenged the existence of singular truths and the notion of universality (Dahlberg et al., 2013; Pacini-Ketchabaw \& Pence, 2005). This work to rethink early childhood not only reimagined childhood itself, but critically challenged the role of ECE institutions and professions, and ultimately the image and role of the early childhood educator, in upholding particular, narrowly defined notions of quality pedagogical practices. Grounded in a reconceptualist framework, the project is built on the understanding that quality ECE is the result of the interaction of diverse physical, pedagogical, and cultural forces and factors. The IQ Project draws on scholarship that views quality beyond dominant quality indicators (e.g., regulations that set standards for structural factors such as group size, adult-child ratios, and training levels of caregivers, as well as levels of literacy, numeracy and school preparedness in young children). Leaning on this scholarship that positions quality as understood historically and across local contexts and diverse cultures, the project is designed to open up spaces to consider local voices and contextual factors as integral influences on quality in early years programming (Dahlberg et al., 2013; Osgood, 2010; Pacini-Ketchabaw \& Pence, 2011). With an understanding that quality involves the ongoing shaping of positive early childhood environments, it is critical to develop educators' pedagogical learning that addresses these diverse forces and factors.

This approach to educators' pedagogical development and practice corresponds with social constructivist conceptualizations of professional learning where (a) learners are recognized as bringing prior learning and experience to any "new" learning opportunity, (b) learning is understood as taking place over time rather than in isolated moments, and (c) learners are supported to critically reflect on their current and developing knowledge (Bowne, Cutler, DeBates, Gilkerson \& Stremmel, 2010; Cochrane-Smith \& Lytle, 2001). Utilizing a social constructivist lens, the IQ Project recognizes the education of young children as a political, situated, complex, and always emerging practice. Learning to teach, both initially and continuously, is more than acquiring 
the technological skills that help children reach predetermined goals; it is to continuously explore what it means to teach/live/practice in an unstable, unpredictable, always emerging world (Hodgins, 2014; Kummen, 2014; Lenz Taguchi, 2010; Pacini-Ketchabaw et al., 2015; Thompson, 2015). Building on their previous writings, CochranSmith and Lytle (2006) argue strongly that "the model of teacher development as training and retraining is retrograde and is inconsistent with contemporary understandings of teaching and learning" (pp. 687-688). They assert that teacher education should not be a training event, but that the focus should be on learning, which includes attending to the beliefs, values, attitudes, and knowledges that student teachers bring to teacher education and educators in practice bring to their early learning classrooms. They write that

students and teachers need to see that teaching requires the intentional forming and reforming of frameworks for understanding practice. It is about how students and their teachers construct the curriculum, commingling their experiences, their cultural and linguistic resources, and their interpretive frameworks. Teaching also entails how teachers' actions are infused with complex and multilayered understandings of learners, culture, class, gender, literacies, social issues, institutions, "herstories" and histories, communities, materials, texts, and curricula. (p. 691)

With such an understanding, conditions for professional learning as an action research process to be carried out within educators' situated contexts of learning are needed (Vandenbroeck et al., 2016). The IQ Project has endeavoured to generate such conditions within learning-collective spaces. With the project's collaboration with the university and community ECE programs in one of our geographical sites, this learning collective has been extended. It is imperative to stress that we use the term learning collective, not as a label for a group of individuals (a noun) but rather as an ongoing knowing, being, and doing (a verb) of collaborative pedagogical practices. In the analysis that follows, we explore conditions for living professional learning as a situated collaborative pedagogical practice.

\section{Becoming educators with/in learning collectives}

Veronica Pacini-Ketchabaw and Alan Pence (2011) strongly argue for early childhood education to make space for more contextually situated curricula and pedagogies that reflect the lives of $21^{\text {st }}$-century children. Many of the educators who participated in the IQ Project indicated that being a part of this project had strengthened their pedagogical and curricular choices (Pacini-Ketchabaw \& Hodgins, 2017). Participants noted the importance of being a part of an ECE learning collective, where they can share practice moments and think with innovative ideas together with other educators, to keep them engaged in their own pedagogical development. As one of the university-community partnership site participants described, "being in the project has helped me to discover my own values and beliefs and in turn I am able to be open to hear others' perspectives and ideas, deepening my knowledge and understanding of quality ECE” (Educator participant survey response).

The educators who participated in the university-community collaboration also reported that this new formalized collaboration was very successful and that there were tremendous benefits to bringing together what are often separate entities in the ECE profession. In the sections that follow we explore the success of the IQ Project's pedagogical development model by attending to three key practices the model supports within a collective of learning: inquiry-based learning, making learning visible, and pedagogical facilitation support. In these subsections we primarily focus on the project engagement and feedback of the participants within the university-community collaboration to highlight that (a) the model is as relevant for early professional learning as it is for ongoing professional learning, (b) bringing together educator training and professional development enhances everyone's 
professional learning, and (c) there is value in creating conditions for pedagogical development within learning collectives as part of the culture of ECE practice.

Inquiry-based learning

As described in the introduction, Vandenbroeck and colleagues (2016) identified four factors for successful continuous professional development initiatives. The first two factors they included put forward as necessary conditions "a coherent pedagogical framework or learning curriculum that builds upon research and addresses local needs" and "the active involvement of practitioners in the process of importing education practice enacted within their settings" (p. 4). They summarized that "professional development initiatives based on research-based enquiry or action research can help staff reflect on their pedagogical practice and therefore contribute to its ongoing development" (p. 4). The IQ Project's pedagogical development model supports the continued implementation of the province's Early Learning Framework (Government of British Columbia, 2008a, 2008b) and uses a participatory action research model to engage early childhood practitioners to reflect on knowledge, experiences, values, and pedagogy (MacNaughton \& Hughes, 2008). The framework outlines key goals within four areas of early learning, but because "there are no preset ways to promote" these, educators are not provided with a step-by-step blueprint for practice. Rather, they are provided "questions for reflection to guide people who care for and educate children" (Government of British Columbia 2008a, p. 17). This reflective process generates a richer, contextually meaningful and relevant curriculum for early childhood educators that supports diverse understandings of quality care for children in BC.

In the IQ Project model, educators are supported to design, execute, and evaluate inquiries or projects within their practice settings as an integral part of their contextually meaningful and relevant curriculum. These are initiated and implemented by educators in collaboration with their program. In BC, the Ministry of Education promotes project-based learning for both early and school-age learning, and several other provinces in Canada so the same (e.g., Alberta, Ontario, Saskatchewan). Glenda MacNaughton and Patrick Hughes (2008) explain that "the roots of inquiry-based learning lie in John Dewey's problem posing approach to learning in education; and to constructivist and socio-constructivist theories of learning that emphasize our capacity to construct our own knowledge about the world and to make new meanings about it" (p. 51). In Reggio Emilia the term project, or progettazione, rather than inquiry, is used "to describe the multiple levels of action ... that are carried out in the dialogue between children and adults" (Rinaldi, 2006, p. 132). Educators in the IQ Project are encouraged to explore, experiment, and learn together through collaborative inquiries lived in their practices. Inquiry work is shared and discussed in the programs (e.g., with the children and families, in team meetings) and at the project learning circles. Inquiries/ projects are intended to support both children's and adults' learning (for examples, see Hodgins, 2014; Kummen, 2014; Pacini-Ketchabaw et al., 2015; Thompson, 2015).

Participants reported that their practice with inquiry-based learning, being a teacher-as-researcher (Rinaldi, 2006; Lenz Taguchi, 2010), was strengthened. One participating educator described that her involvement in the project had shifted her understanding of quality in ECE by giving her "a better understanding on how projects open up more avenues to children's learning" (Educator participant survey response). Another noted, "Now I think 'quality' must include engaged teacher-researchers who reflect together (not just about enviro, curriculum, etc.)" (Educator participant survey response, underline in participant response). Educators pointed out that this approach is as much about learning more about and supporting children's learning as it is about investigating educators' own. One educator commented: "For me the quality in ECE is consistently and continually looking to grow our understanding of children's learning and how we can expand their and our own thinking; a culture of inquiry" (Educator participant survey response). 
Adding the university ECE students into the project's participating programs changed the collective thinking. Having the student educators join the educators' inquiry work with the children opened up new spaces to extend curriculum activities. One of the program's educators commented that they "could have another thread of the inquiry going and gain more perspectives" (Educator participant survey response), while another said: "I try more new things, we are extending projects longer, we get more new ideas" (Educator participant survey response), as a result of having the student educators join their projects. Student educators brought their understandings and curiosities, including their postsecondary classroom readings, activities, and discussions, to the ECE program. As one educator reported, the "student-educators always bring their own, unique perspectives to the centre, which helps us keep in touch with the latest practices as well as to see things from their point of view" (Educator participant survey response). Intentionally bringing the student educators into the project's inquiry-based learning collective is congruent with Avgitidou, Pnevmatikos, and Likomitrou's (2013) argument that the "opportunities for preservice teachers to systematically observe children in educational settings, followed by discussion of specific examples from the observations and reflection on their thoughts, assumptions, and interpretations, [are] crucial for a transformation of framework theory to take place" (p. 402). One student educator participant eloquently and succinctly summed up her experience by stating, "I saw theory making in motion" (Student educator feedback). Another student educator articulated that practicum was more than practising technologies of teaching in the comment "To me, doing practicum is a process of learning" (Student educator feedback).

\section{Making learning visible}

The third key factor identified by Vandenbroeck and colleagues (2016) for successful professional learning is a focus on practice-based learning that takes place in constant dialogue with colleagues, parents, and local communities. Both the IQ Project model and the BC Early Learning Framework (ELF) are predicated on the understanding that investigating, experimenting with, and extending children's and adults' learning through inquiry-based curriculum and pedagogies in their own programs generates contextually relevant ECE environments. These investigations, experimentations, and extensions are supported through pedagogical narrations, a tool for engaging in critically reflective dialogue about pedagogical practice that is often referred to as pedagogical documentation (Government of British Columbia, 2008b; Pacini-Ketchabaw et al., 2015). Described as an "ongoing, cyclical process that occurs in and with a community of learners," it is a process that involves observing and documenting moments of practice; interpreting documentation individually and collectively to make learning visible; deepening the interpretation through sharing and making public the description; linking the narration to pedagogical practice; and evaluating, planning, and starting the process again (Government of British Columbia, 2008b, p. 13).

Pedagogical facilitators in the IQ Project encourage and support participating educators to produce, reflect with, and discuss pedagogical narrations within their practice. Student educators who participated in the universitycommunity collaboration produced and engaged with pedagogical narrations as part of the project programs' practice of inquiry-based learning, and as part of their university ECE program's course readings, assignments, and classroom discussions. While often described as a process for making children's learning visible, pedagogical narration is also an avenue for making educators' professional learning visible (Hodgins, 2014; Pacini-Ketchabaw et al., 2015; Thompson, 2015) and student educators' learning visible (Bowne et al., 2010; Kummen, 2014; Lenz Taguchi, 2010). Bowne and colleagues' (2010) three-year research study with ECE students, which explored collaborative dialogue and documentation as tools of pedagogical inquiry, strongly put forward that ECE teacher education needs to provide opportunities for students to "talk with one another to exchange ideas, work on problems, revise thinking, share understanding, accommodate when differences arise and create documentation pieces to make learning visible" (p. 57). By making aspects of a program's inquiry work visible, student educators and the pedagogical facilitator could (more easily) be brought into the program's collaborative inquiry. In the 
words of a participant, "It was great that students picked up on current interests in our program and extended our explorations on a long-term basis" (Educator participant survey response).

By engaging in pedagogical narrations, participants reported an increased understanding of their own and each other's practice choices. One educator stated:

The project has helped me to listen to others and to reflect on future actions before jumping in. Having an understanding of those around me and how decisions affect them, as well as the work around me, changes the way I move forward. (Educator participant survey response)

These opportunities for dialogue (e.g., during LCs, centre visits, and team meetings) enhanced educators' abilities and comfort levels to speak about their pedagogical practice. One educator said, "I feel a lot more comfortable when sharing/expressing my thoughts/ideas. I feel that our team has become a lot closer and we have been able to work together/reflect upon ideas/discuss challenges/assist one another" (Educator participant survey response). Another educator described "definitely asking educators more questions in their projects \& contributing more of [her] thoughts" (Educator participant survey response). Making pedagogical understandings and choices public within a learning collective not only supports student educators' and educators' ongoing pedagogical development and practice, but is integral to building a culture of practice that can articulate, deliver, and advocate for rich, contextually meaningful, and relevant curriculum and pedagogies that support diverse understandings of quality care (Dahlberg et al., 2013; Lenz Taguchi, 2010; Pacini-Ketchabaw et al., 2015).

\section{Pedagogical facilitation support}

The fourth factor for successful continuous professional development initiatives that Vandenbroeck and colleagues (2016) identified is "the provision of enabling working conditions, such as the availability of paid hours for noncontact time and the presence of a mentor or coach who facilitate[s] practitioners' reflection in reference groups" (p. 4). A key feature of the IQ Project's pedagogical development model is the community pedagogical facilitator position. Pedagogical facilitators are responsible for helping to create and sustain situated quality ECE programs through supporting educators to (a) continue to implement the BC ELF; (b) design, execute, and evaluate inquiries/ projects within their practice settings, and (c) engage in critically reflective dialogue about pedagogical practice through pedagogical narrations. Pedagogical facilitators play a role similar to that of pedagogistas in the centres of Reggio Emilia, Italy: immersing themselves in the centres, supporting the educators' efforts to engage with children and families in innovative, critically reflective practice, and extending the practice of the educators and the children by introducing new ideas and materials (Rinaldi, 2006). One of the ripple effects of the IQ Project's work since 2005 is the take-up of the pedagogical facilitator role in some larger institutional settings in BC (e.g., University of Victoria Child Care Services, UBC Child Care Services, Capilano University's Children's Centre) and the development of university ECE courses for student learning about this role (i.e., Capilano University EDUC 379 and EDUC 380, and University of Victoria CYC 481).

Participant educators in all three of the project's geographical sites commented that the pedagogical facilitator was instrumental in supporting their practice, helping them to deepen their critical reflection and confidence and think on a deeper level (Pacini-Ketchabaw \& Hodgins, 2017). Within the university-program initiative, one participant educator described it thus:

Having the pedagogical facilitator / university instructor helped us adopt an inquiry stance along with the children and create a culture of inquiry. She helped out and taught us how to observe and document the children's thinking, ideas, and learning and how to interpret and analyze what we've noticed, how to express our own thinking and ideas as we interact with 
children. (Educator participant survey response)

Many of the participating educators expressed how valuable this pedagogical facilitator role was in supporting the children's, student educators', and participating educators' learning in the classroom. Several educators in the university-community collaboration pointed out that because the pedagogical facilitator had been deeply involved in their classrooms, she could better prepare students who were joining their environment. For example, one said: "I felt the students got a lot of support from her and they come in with background history of what the children have already been exploring. Therefore, we were also able to work with the students right away" (Educator participant survey response). Another participating educator wrote that this enabled student educators to better "engage with our current curriculum explorations [and] more deeply connect with what we were doing" (Educator participant survey response).

Participating educators also described that the "dual role" of the pedagogical facilitator in the university-community collaboration helped facilitate educators and student educators in the program learning from each other more than if they were working in a practicum on their own. When asked how this collaboration with the university's training program impacted their practice, one educator responded that it "encourages reflective practice among our team as we observe student-educators and a facilitator practicing the latest research and learning tools. It also enhances our program and staff's professional development as we support students in their learning" (Educator participant survey response). Another wrote:

I liked that there was a dual role and felt that I was learning alongside of her and the students. Having a pedagogical facilitator in these roles enabled me to really be open to new ideas as well as be open to the perspectives of others too. (Educator participant survey response)

Student educators also commented that being part of the learning collective with educators and the pedagogical facilitator (their university instructor) was integral to their professional learning. One student educator noted, "They guided me to make wise decisions that reflected my values and beliefs. I would not have survived my practicum without the support and guidance from my mentor teachers and [the PF/student's instructor]" (Student educator feedback). One student educator shared this letter in an unsolicited email to the coordinator of the department and dean about her experience in the learning collective:

Through this learning environment, I was able to explore my potential as an educator. This meant I experienced first-hand the struggles and immense satisfaction that comes with being involved in project based learning with children. I am sharing this experience with you because of the importance the pedagogical facilitator played in the process. Her role was important for two reasons. First, she provided support to the [site] educators by helping them develop a curriculum congruent with [the training institution's] pedagogical approach to early childhood educations. Second, she provided weekly constructive feedback with regards to the direction of my educational development and future project explorations. Her presence and influence made it possible for myself and the other educators to work alongside each other in a cocollaborative learning environment. There was no hierarchical system our role as educators [was] to learn with and from each other and to work together to further the children's learning. In seeing the positive impact this experience has had on my practice, I strongly encourage [the training institution] to continue investing in having pedagogical facilitators at practicum placement sites. (Student educator feedback)

The university-program collaboration extended the role of the postsecondary instructor in ways that respond to 
the calls made by researchers to provide student educators with intentional and guided opportunities to reflect on their observations of and practices with young children in ECE settings (Avgitidou et al., 2013; Bowne et al, 2010). The value of extending the learning collective to more intentionally include student educators with educators and the pedagogical facilitator/instructor in practice settings is summed up by the following feedback from one of the educator participants in this initiative.

The relationship between the facilitator/educators and students was a positive change in the way we look at students and the support we receive from the university. Being in the field of ECE for 20 years I have had many opportunities to observe the relationships between educators and students. These observations were mainly negative with feelings of resentment, not being supported, no educator given to being a mentor educator for students and lack of student preparedness were concerns of the educators. The implementation of this project has changed the way students and educators work within the program and with children. Some things we did to create change: facilitator working w/programs and with students; dialogue w/educators about their concerns limitations, understanding of working w/students, met to talk about what it could look like and how they could be supported; implementation of process from university to centre, and centre to program and student. This has created a collaborative environment where educators are feeling supported, students are welcomed and included for the value and learning they bring to the program, and the society feels as if they are gaining from the experience. Win, win, win for all involved. (Educator participant comment written on the back of the survey)

\section{Conclusion}

We have presented a model of pedagogical development for educators' professional learning where pedagogical facilitators support a cluster of community ECE programs and their educators and practicum students. It is a model grounded in a social constructivist conceptualization of learning, a conceptualization that recognizes all learning as coconstructed with/in socio-material-historical-cultural-political relationships and contexts. With this understanding, professional learning, both initially and continuously, is understood as more than acquiring technological skills to help children and educators reach predetermined goals. It is an approach to pedagogy that Hillevi Lenz Taguchi (2010) refers to as ethics of immanence and potentialities, an approach that aims to "transform educational practices so that they can be about challenging children's, students' and teachers' potentialities and capacities to act and be inventive in the process of collaborative experimentation and production of concepts and knowing" (p. 177). Engaging in pedagogical practices with this approach "does not treat pedagogical work as being exclusively about trying to get children, students, and teachers to reach pre-set goals or pre-set learning contents" (p. 177). Rather, the concern for professional learning is how to support educators' becoming-pedagogies in an unstable, unpredictable, always emerging world.

We shared the IQ Project's model of pedagogical development through learning collectives as an avenue to support becoming-pedagogies with/in sites of practice. With the university-community partnership that more deeply connected ECE programs and their educators' ongoing professional learning with an ECE training institution and its preparation of student educators, the model's extended learning collective reaches beyond traditional understandings and practices of educator training and professional development. In line with Vandenbroeck and colleagues' (2016) presentations of key factors for successful continuous professional development, we detailed the impact of the model's three key conditions_inquiry-based learning, making learning visible, and pedagogical facilitation support-on educators and student educators who participated in the project. The participant responses 
speak of relationships and commitments that were strengthened as a result of their experiences doing early childhood education within this model of pedagogical development. Through our analysis we have argued that the model is as relevant for early professional learning as it is for ongoing professional learning, and that bringing together student educator training and professional development initiatives enhances everyone's professional learning. The project's success is reflected in its accruing waitlist for participation and the university partner's commitment to support a second pedagogical facilitator/instructor who will work with another cluster of programs and group of student educators.

We have also presented the IQ model as a provocation to consider how learning collectives can be(come) part of ECE culture. Over the past 12 years, the IQ Project has grown and researched a model of pedagogical development to foster professional learning as an ongoing action research process to be carried out within situated contexts; it has also demonstrated the value of supporting professional learning through local learning collectives (see http://www.veronicapaciniketchabaw.com/reports/). However, current conditions are such that access to such professional learning in $\mathrm{BC}$ is sporadic, limited by resources, and dependent on the goodwill of individuals or institutions. Despite the best intentions of educators, advocates, and researchers, ultimately innovative initiatives are limited in scope without a cohesive, robust and fully integrated ECE system (Dahlberg et al., 2013; Osgood, 2010; Rinaldi, 2006; Vandenbroeck et al., 2016). The IQ Project demonstrates the need to move beyond ECE training and professional learning as individual responsibilities and single events to a collective culture of ECE practice that is truly committed to the values espoused in the frameworks it creates and endorses. It is not our suggestion that this model is a panacea for early years practice. We recognize that the profession faces enormous challenges within piecemeal and underfunded ECE systems in this province and beyond. Yet, we believe that a commitment to learning collectives is a step in the right direction for creating conditions of possibility for professional becomings and flourishing $21^{\text {st }}$-century childhoods. 


\section{References}

Avgitidou, S., Pnevmatikos, D., \& Likomitrou, S. (2013). Preservice teachers' beliefs about childhood: Challenges for a participatory early childhood education? Journal of Early Childhood Teacher Education, 34(4), 390-404. doi:10.1080/10901027.2013.845633

Bowne, M., Cutler, K., DeBates, D., Gilkerson, D., \& Stremmel, A. (2010). Pedagogical documentation and collaborative dialogue as tools of inquiry for preservice teachers in early childhood education: An exploratory narrative. Journal of the Scholarship of Teaching and Learning, 10(2), 48-59. Retrieved from http://josotl.indiana.edu/index

Cochran-Smith, M., \& Lytle, S. (2001). Beyond certainty: Taking an inquiry stance on practice. In A. Lieberman \& L. Miller (Eds.), Teachers caught in the action: Professional development that matters (pp. 45-58). New York, NY: Teachers College.

Cochran-Smith, M., \& Lytle, S. L. (2006). Troubling images of teaching in No Child Left Behind. Harvard Educational Review, 76(4), 668-697.

Dahlberg, G., Moss, P., \& Pence, A. (2013). Beyond quality in early childhood education and care: Languages of evaluation (3 ${ }^{\text {rd }}$ ed.). New York, NY: Routledge.

Government of British Columbia. (2008a). British Columbia early learning framework. Victoria, BC: Crown Publications, Queen's Printer for British Columbia. Retrieved from http://www.bced.gov.bc.ca/early_learning/pdfs/early_learning_framework.pdf

Government of British Columbia. (2008b). Understanding the British Columbia early learning framework: From theory to practice. Victoria, BC: Crown Publications, Queen's Printer for British Columbia. Retrieved from http://www.bced.gov.bc.ca/early_learning/pdfs/ from_theory_to_practice.pdf

Hodgins, B. D. (2014). Playing with dolls: (Re)storying gendered caring pedagogies. International Journal of Child Youth and Family Studies, 5(4.2), 782-807.

Kummen, K. (2014). When matter in the classroom matters: Encounters with race in pedagogical conversations. International Journal of Child, Youth, and Family Studies, 5(4.2), 808-825.

Lenz Taguchi, H. (2010). Going beyond the theory/practice divide in early childhood education: Introducing an intra-active pedagogy. New York, NY: Routledge.

MacNaughton, G., \& Hughes, P. (2008). Doing action research in early childhood studies. London, UK: Open University Press.

Osgood, J. (2010). Reconstructing professionalism in ECEC: The case for the "critically reflective emotional professional," Early Years, $30(2), 119-133$.

Pacini-Ketchabaw, V., \& Hodgins, B. D. (2017). The community early learning and child care facilitators project: Evaluation $2016-2017$. Retrieved from http://www.veronicapaciniketchabaw.com/reports/

Pacini-Ketchabaw, V., Nxumalo, F., Kocher, L., Elliott, E., \& Sanchez, A. (2015). Journeys: Complexifying early childhood practices through pedagogical narration. Toronto, ON: University of Toronto Press.

Pacini-Ketchabaw, V., \& Pence, A. (2005). Contextualizing the reconceptualist movement in Canadian early childhood education. In A. Pence \& V. Pacini-Ketchabaw (Eds.), Canadian early childhood education: Broadening and deepening discussion of quality (pp. 5-20). Ottawa, ON: Canadian Child Care Federation.

Pacini-Ketchabaw, V., \& Pence, A. (2011). The postmodern curriculum: Making space for historically and politically situated understandings. Australasian Journal of Early Childhood, 36(1), 4-8.

Pence, A., \& Pacini-Ketchabaw, V. (2006). The investigating "quality" project: Challenges and possibilities for Canada. Interaction, 20(3), 11-13.

Rinaldi, C. (2006). In dialogue with Reggio Emilia. New York, NY: Routledge.

Thompson, D. (2015). Caring, dwelling, and becoming: Stories of multiage child care (Doctoral dissertation). Retrieved from http://hdl. handle.net/1828/5939 
Vandenbroeck, M., Peeters, J., Urban, M. \& Lazzari, A. (2016). Introduction. In M. Vandenbroeck, M. Urban, \& J. Peeters (Eds.), Pathways to professionalism in early childhood education and care, (pp. 1-14). London, UK: Routledge. 